\title{
Interrelations of Calcium and Rubidium Absorption by Excised Roots of Barley and Plantain ${ }^{1}$
}

\author{
J. C. Noggle 2 , C. T. de Wit ${ }^{3}$, and A. L. Fleming ${ }^{4}$
}

\section{ABSTRACT}

The uptake rates of $\mathrm{Rb}$ and $\mathrm{Ca}$, applied alone or together, by excised barley and plantain roots were compared. The barley roots absorbed $\mathrm{Rb}$ at a faster rate than $\mathrm{Ca}$, whereas the reverse was true for plantain roots. The presence of $\mathrm{Ca}$ increased the rate of $\mathrm{Rb}$ uptake by barley roots, but the presence of $\mathrm{Rb}$ had very little effect upon the Ca uptake. The uptake rate of either ion by plantain was reduced by the presence of the other ion.

Calculations indicate that the depressing effect of one ion on the uptake of the other by plantain was due predominantly to ionic competition when the ions were present in the concentration range of $10^{-2} \mathrm{~N}$, but factors in addition to competition were responsible in the concentration range of $10^{-4} \mathrm{~N}$. The significance of the differences in response of the two species is discussed.

Collander (3) Grew Different species of plants in $G$ solutions containing equivalent amounts of $\mathrm{K}$ and $\mathrm{Ca}$ and found that oats accumulate much more $\mathrm{K}$ than $\mathrm{Ca}$ while Plantago lanceolata accumulates $\mathrm{K}$ and $\mathrm{Ca}$ in about equal amounts. This difference in cation selectivity between plant species, which has been confirmed by de Wit and Dijkshoorn (unpublished) for Dactylis glomerata and $P$. lanceolata, may be associated with the utilization of the ions during growth or related to the cation uptake mechanism by the roots. With the assumption that the uptake of cations by exised roots is affected to only a small extent by cation utilization, the interrelations between $\mathrm{Ca}$ and $\mathrm{Rb}$ uptake by excised roots of barley (Hordeum vulgare) and plantain $(P$. lanceolata) were compared.

${ }^{1}$ Contribution from the U. S. Soils Laboratory, Soil and Water Conservation Research Division, ARS, USDA, Beltsville, Md. Presented before Div. IV, Soil Sci. Soc. Am., Ithaca, N. Y. Aug. 20, 1962. Received Mar. 4, 1963. Approved May 13, 1963. "Soil Scientist.

${ }^{3}$ Formerly Visiting Soil Scientist, Present Address: Institute for Biological and Chemical Research on Field Crops and Herbage, Bornse steeg 65, Wageningen, The Netherlands. ${ }^{\dagger}$ Physical Science Aid.
Competitive Relations

The $\mathrm{n}$ equations

$$
r_{i}=\frac{b_{i} C_{i}}{b_{1} C_{1}+--b_{i} c_{i}+--+b_{n} c_{n}+1} R_{i}(i=1,2,--n)
$$

with proper designations for the symbols are widely used to describe competitive phenomena in physical and chemical engineering, physical chemistry, biochemistry, plant ecology, and animal ecology.

In the case of ionic uptake $C_{1},-C_{i},-C_{n}$ represent concentrations of ions of the same sign in the root medium and $r_{i}$, the absorption, adsorption, or sorption of the ionic species by roots, and $b_{i}$ and $R_{i}$ are constants for each ionic species. $R_{i}$ is the value of $r_{i}$ for infinite concentration of $\mathrm{C}_{i}$. Epstein and Hagen (6), Fried and Noggle (7), and others used these equations to evaluate whether two ions affect each other competitively.

If one of the ions, in a n-ion system, is varied and the others are kept constant, equation [1] reduces to

$$
\mathrm{r}_{1}=\frac{\left(\mathrm{b}_{1} / \mathrm{K}\right) \mathrm{C}_{1}}{\left(\mathrm{~b}_{1} / \mathrm{K}\right) \mathrm{C}_{1}+1} \mathrm{R}_{1}
$$

in which

$$
K=1+\sum_{i=2}^{n} b_{i} C_{i}=\text { constant }
$$

Fried and Noggle (7) tested the validity of this equation over a wide concentration range and found that for barley roots the results can be described with two equations [2], one being predominant at concentrations in the order of $10^{-4}$ equivalents (eq.) per liter and the other at concentrations around $10^{-2}$ eq. per liter. Bear (1), Dijkshoorn (5), Sutcliffe (10), and Said (9) used replacement series to study the effect of one ion on the other. These are series of treatments in which the total cation content of the solution is constant but the ratios of the cations vary.

For a replacement series of the ions 1 and 2 , equation [1] can be simplified by substituting the identity 


$$
K=K \frac{C_{1}+C_{2}}{C_{1}+C_{2}}=K \frac{C_{1}+C_{2}}{a} \text { for } K=1+\sum_{i=3}^{n} b_{i} C_{i}=\text { constant }
$$

in equation [1].

This gives

$$
r_{1}=\frac{k_{12} C_{1}}{k_{12} C_{1}+C_{2}} R_{1}^{\prime}
$$

and

$$
\mathrm{r}_{2}=\frac{\mathrm{C}_{2}}{\mathrm{k}_{12} \mathrm{C}_{1}+\mathrm{C}_{2}} \mathrm{R}_{2}^{\prime}
$$

with

$$
k_{12}=\frac{b_{1} / K+(1 / a)}{b_{2} / K+(1 / a)}, R_{1}{ }^{\prime}=\frac{b_{1} / K}{b_{1} / K+(1 / a)} R_{1} \text { and } R_{2}{ }^{\prime}=\frac{b_{2^{\prime}} / K}{b_{2} / K+(1 / a)} R_{2} .
$$

Hence a competitive relation as described by equation [1] may exist if for any concentration ratio within a replacement series, the sum $r_{1} / R_{1}{ }^{\prime}+r_{2} / R_{2}{ }^{\prime}=1$, that is, if the curves $r_{1} / R_{1}^{\prime}$ vs. $C_{1}$ and $r_{2} / R_{2}^{\prime}$ vs. $C_{2}$ are both curved to the same extent but in opposite directions. A detailed discussion of the interrelations for this type of competition was given by De Wit (4). A more critical test of the applicability of equation [1] involves calculation of the constants $\mathrm{b} / \mathrm{K}$ and $\mathrm{R}$ for both ions by matching equation [2] to the observations from a concentration series and checking whether substituting these values into equations [3] will yield curves to fit the observed data of the replacement series.

It is often supposed that the first step in ionic uptake is an exchange reaction. This being the case, it may be that the competitive interrelations between a monovalent ion and a divalent ion are more complicated than indicated by equation [1]. For resin systems this has been analyzed by Heald et al. ( 8 ). Their treatment and data show that experiments must be executed rather accurately over a wide concentration range to show these complications. Neither the accuracy nor the range of concentrations used in the present study permit the use of an equation other than [1].

\section{EXPERIMENTAL TECHNIQUES}

Barley roots were obtained from 7-day-old seedlings grown in a solution of $4 \times 10^{-4}$ eq. $\mathrm{CaSO}_{4}$ per liter, as described by Epstein and Hagen (6). About 24 hours before the beginning of an experiment, the $\mathrm{CaSO}_{4}$ solution was replaced by demineralized water.

Plantain was removed from the field and the roots and tops were clipped. The plants were allowed to regrow for 3 to 4 weeks in a half-strength Hoagland nutrient solution with micro-nutrients and iron chelate as developed by Said (9). About 48 hours before beginning the experiment, the nutrient solution was replaced by demineralized water in order to remove $\mathrm{Ca}$ from the surface of the roots. After removal of the roots the tops were clipped and the plants were returned to the nutrient solution for regrowth and use in subsequent experiments.

The roots were excised shortly before the beginning of an experiment and washed in demineralized water. Samples of an estimated $0.5 \mathrm{~g}$. were transferred to the treatment solutions at the beginning of the sorption period. The treatment solution was decanted at the end of the sorption period and adhering solution was removed by washing one minute with demineralized water. The adhering water was removed by blotting the roots with tissue paper before determining the fresh weight. Roots containing $\mathrm{Ca}^{45}$ were ashed at $400^{\circ} \mathrm{C}$. before $\mathrm{Ca}^{45}$ was determined.

Chloride salts of $\mathrm{Ca}$ and $\mathrm{Rb}$ were used in all cases. When both $\mathrm{Ca}$ and $\mathrm{Rb}$ uptake were to be determined from a mixture of the two ions, sufficient solution was prepared and divided into two portions. One portion was tagged with $\mathrm{Rb}^{56}$ and the other with $\mathrm{Ca}^{45}$. Solution volume to root ratios were sufficiently large to limit exhaustion to within $25 \%$.

Fried and Noggle (7) showed that $\mathrm{Rb}$ and $\mathrm{K}$ are practically indistinguishable by excised barley roots in short-time sorption studies so that within rather narrow limits it is allowed to read $\mathrm{K}$ uptake for $\mathrm{Rb}$ uptake.

\section{RESULTS AND DISCUSSIONS}

\section{Time Series}

The uptake of $\mathrm{Rb}$ by barley from a solution with $10^{-4}$ eq. $\mathrm{RbCl}$ per liter in the absence and presence of $10^{-3}$ eq. $\mathrm{CaCl}_{2}$ per liter is given in figure 1, left; figure 1, right, represents the data during the first 40 minutes of sorption plotted on a larger scale. The uptake rate in the presence of $\mathrm{Ca}$ does not change appreciably during the 3 hours, but in the absence of $\mathrm{Ca}$ a much smaller rate is established after 50 minutes. Although the amount of $\mathrm{Rb}$ associated with the roots is lower during the first 40 minutes, the rate of uptake (slope of line) between 5 and 180 minutes is higher in the presence than in the absence of $\mathrm{Ca}$. The uptake of $\mathrm{Rb}$ by plantain roots from a solution with $10^{-4}$ eq. $\mathrm{RbCl}$ per liter in the absence and presence of $10^{-4}$ eq. $\mathrm{CaCl}_{2}$ per liter during 3 hours is given in figure 2, left. A steady uptake rate is reached after half an hour. Calcium appears to depress the uptake of $\mathrm{Rb}$ during the entire 3-hour period.

The uptake of $\mathrm{Ca}$ from a solution with $10^{-4} \mathrm{eq}$ $\mathrm{CaCl}_{2}$ per liter by plantain is given in figure 2, right. After 40 minutes a steady uptake rate is established which is small compared with the sorption before that time. The sorption of $\mathrm{Ca}$ by barley roots before 40 minutes is often so high, compared with the sorption between 40 and 180 minutes, that it is difficult to establish an uptake rate after 40 minutes.
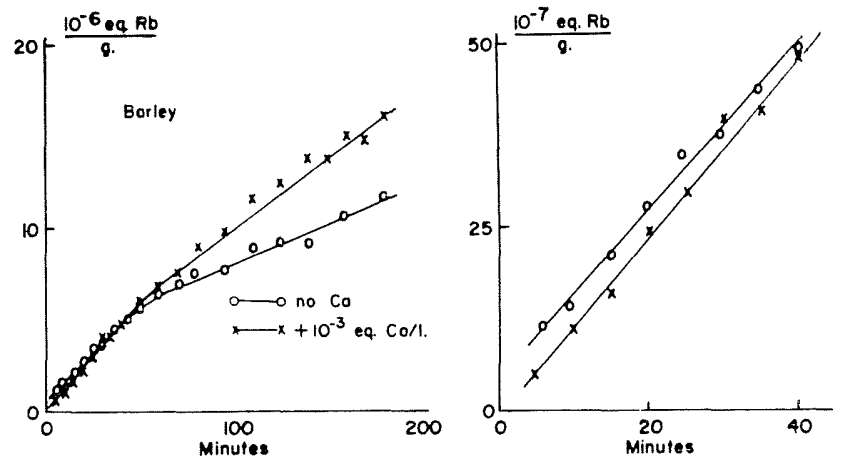

Figure 1-The uptake of $\mathrm{Rb}$ by barley roots from a solution with $1 \times 10^{-4}$ eq. Rb/liter.

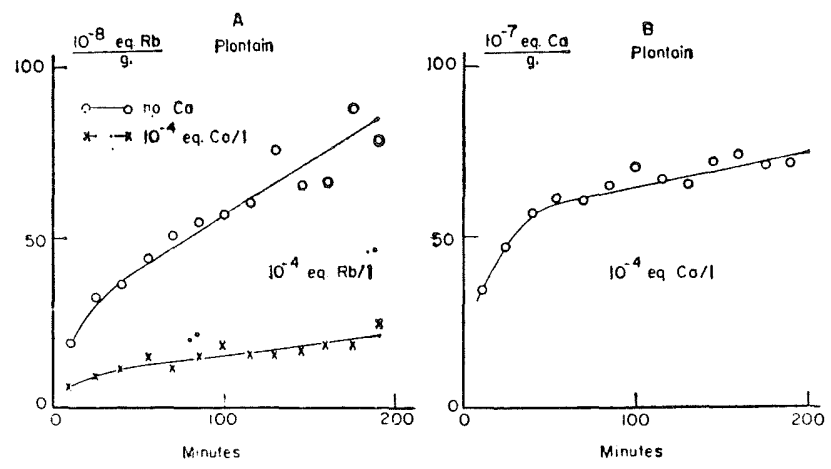

Figure 2-The uptake of $\mathrm{Rb}$ (left) and $\mathrm{Ca}$ (right) by plantain roots from a solution with $1 \times 10^{-4}$ eq./liter. 
Table 1 -Concentrations of $\mathrm{RbCl}$ and $\mathrm{CaCl}_{2}$ used in uptake rate studies.

\begin{tabular}{|c|c|c|c|}
\hline \multicolumn{2}{|c|}{ Concentration series } & \multicolumn{2}{|c|}{ Replacement series } \\
\hline $\mathrm{RbCl}$ & $\mathrm{CaCl}_{2}$ & $\mathrm{RbCl}$ & $\mathrm{CaCl}_{2}$ \\
\hline & & & \\
\hline $\begin{array}{l}0.33 \\
0.67\end{array}$ & $\begin{array}{l}0.00 \\
0.00\end{array}$ & $\begin{array}{l}1.00 \\
0.67\end{array}$ & $\begin{array}{l}0.00 \\
0.33\end{array}$ \\
\hline 1.00 & 0.00 & 0.33 & 0.67 \\
\hline 0.00 & 1.00 & 0.00 & 1.00 \\
\hline 0.00 & 0.67 & & \\
\hline 0.00 & 0.33 & & \\
\hline
\end{tabular}

These time studies show a steady rate of $\mathrm{Rb}$ and $\mathrm{Ca}$ uptake between 40 and 180 minutes. Therefore, in subsequent experiments the sorption of $\mathrm{Rb}$ and $\mathrm{Ca}$ per gram of fresh roots was determined in duplicate after 40 and 180 minutes. The value for the rate of uptake, expressed as equivalents per gram fresh root per 140 minutes, was obtained by subtracting the sorption for 40 minutes from the sorption for 180 minutes.

Experiments at Concentrations Around $10^{-4}$ eq. per liter

The uptake of $\mathrm{Rb}$ and $\mathrm{Ca}$ was studied at the concentrations and combinations as shown in table 1 . It should be noted that only one cation, either $\mathrm{Rb}$ or $\mathrm{Ca}$, is present in a solution of the concentration series, but both $\mathrm{Rb}$ and Ca may be present in the same solution of a replacement series. The sum of $\mathrm{Rb}$ and $\mathrm{Ca}$ is constant in all solutions of a replacement.

The uptake rates for $\mathrm{Rb}$ and $\mathrm{Ca}$ by barley are presented in figure 3 and by plantain in figure 4 . The concentrations of $\mathrm{Rb}$ and $\mathrm{Ca}$, expressed in a scale from 0 to $1 \times 10^{-4}$ eq. per liter, are given along the abscissa in opposite directions. Increasing $\mathrm{Ca}$ concentrations are plotted from right to left on the concentration series so that the uptake rates are more easily compared with the uptake rates of the replacement series.
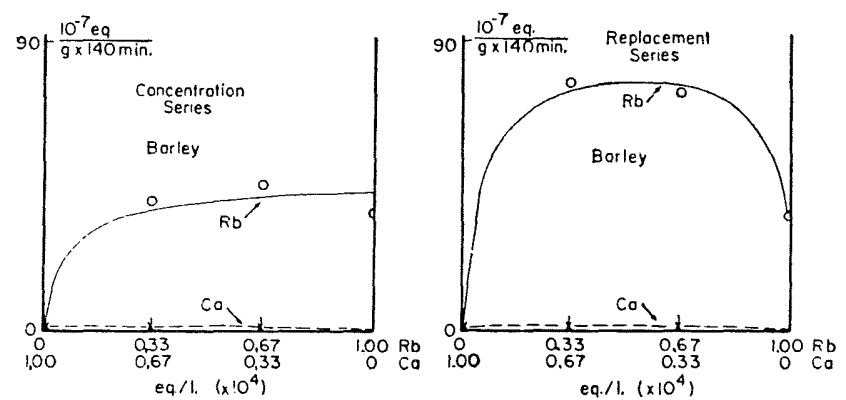

Figure 3-The uptake rate of $\mathrm{Rb}$ and $\mathrm{Ca}$ by barley roots from solutions with a concentration around $10^{-4}$ eq./liter.
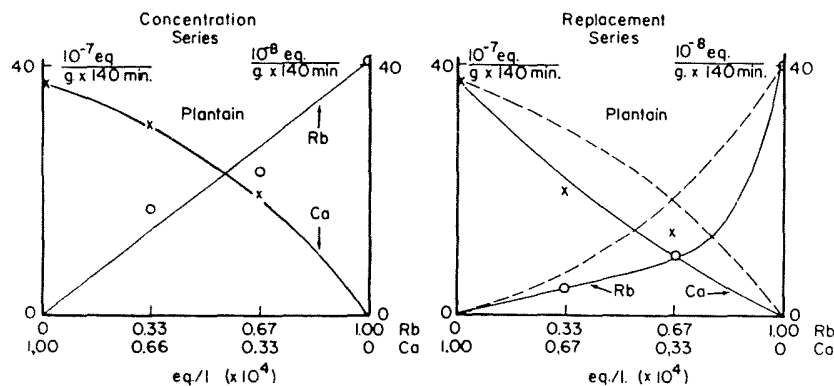

Figure 4-The uptake rate of $\mathrm{Rb}$ and $\mathrm{Ca}$ by plantain roots from solutions with a concentration around $10^{-4}$ eq./liter.
The uptake rate of $\mathrm{Ca}$ by barley roots is negligible compared with the uptake rate of $\mathrm{Rb}$, figure 3 , left. The rate of $\mathrm{Rb}$ uptake appears to double in the presence of $\mathrm{CaCl}_{2}$, figure 3 , right. It has been suggested by Briggs, Hope, and Robertson (2) that the enhancement effect of $\mathrm{Ca}$ on the uptake of $\mathrm{Rb}$ is due to the uptake of the anion which is associated with the $\mathrm{Ca}$. The $\mathrm{Cl}$ concentration is constant in the replacement series which eliminates any effect that the anion might have on the uptake of the $\mathrm{Rb}$. The uptake rate of $\mathrm{Rb}$ from solutions of 0.33 and $0.67 \times 10^{-4}$ eq. $\mathrm{Rb}$ per liter in the presence of $\mathrm{Ca}$ is higher than the uptake rate from a solution of $I \times 10^{-4}$ eq. $\mathrm{Rb}$ per liter in the absence of $\mathrm{Ca}$ while the Cl concentration is constant in the three solutions. This agrees with the results of Viets (11) who found the effect by adding $\mathrm{CaSO}_{4}$, while the uptake rate of $\mathrm{SO}_{4}$ is slow compared to $\mathrm{Cl}$. It is useless trying to recognize competition in these data because of the enhancement effect of $\mathrm{Ca}$ on $\mathrm{Rb}$ uptake.

The uptake rate of $\mathrm{Ca}$ by plantain roots is about 10 times larger than $\mathrm{Rb}$ uptake rate (different scales, figure 4 , left), but it is apparent that $\mathrm{Ca}$ and $\mathrm{Rb}$ decrease the sorption of each other, figure 4, right. Using the uptake rates from the concentration curves in figure 4 , a value of about 2.3 for $\mathrm{k}_{\mathrm{CaRb}}$ is calculated. The values for the uptake rate in a replacement series, calculated with this constant and equation [3], are represented by the dotted lines on the replacement series graph of figure 4 . The observed depressing effect of each ion on the uptake rate of the other is larger than the calculated effect, and since both measured replacement curves are not bent to the same extent, it must be concluded that although competitive effects may play a role some other effect is also present.

\section{Experiments at Concentrations Around $1 \times 10^{-2}$} eq. per liter

The experiments of figures 3 and 4 were repeated at 100-times higher concentrations.

The results are represented in figures 5 and 6 . With
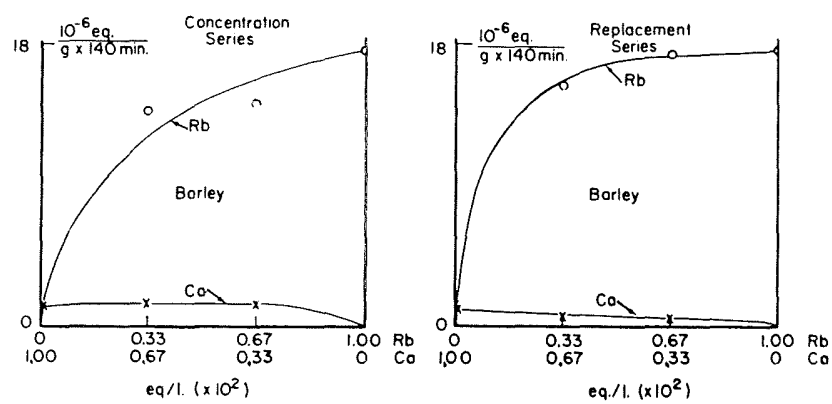

Figure 5-The uptake rate of $\mathrm{Rb}$ and $\mathrm{Ca}$ by barley roots from solutions with a concentration around $10^{-2}$ eq./liter.
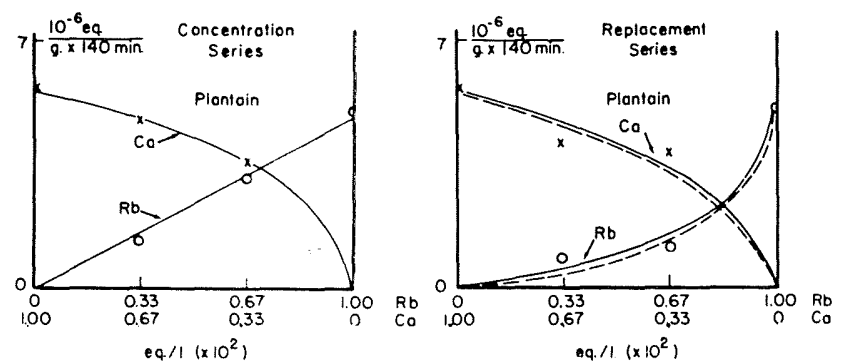

Figure 6-The uptake rate of $\mathrm{Rb}$ and $\mathrm{Ca}$ by plantain roots from solutions with a concentration around $10^{-2}$ eq./liter. 

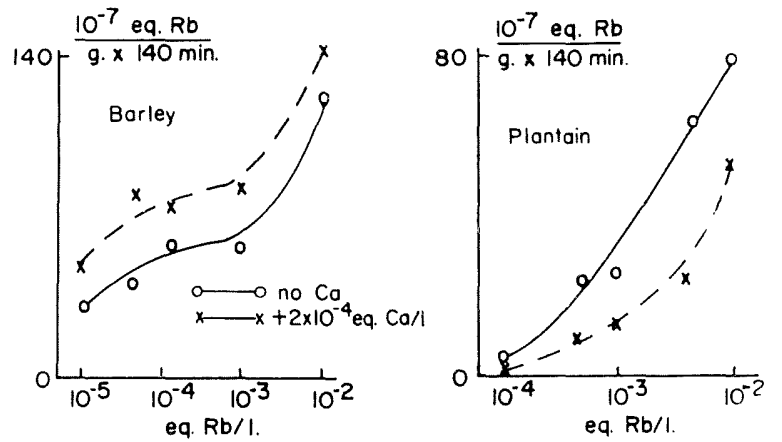

Figure 7-The uptake rate of $\mathrm{Rb}$ by barley (left) and plantain (right) from solutions with $2 \times 10^{-4}$ eq. Ca/liter and varying $\mathbf{R b}$ concentrations.
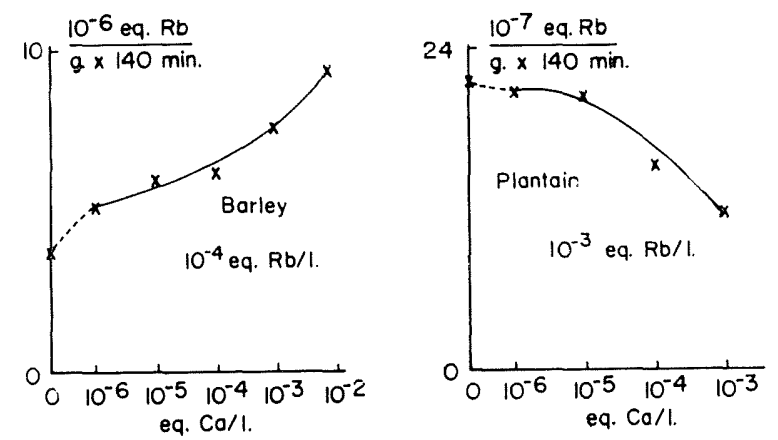

Figure 8-The uptake rate of Rb by barley (left) and plantain (right) from solutions with constant $\mathrm{Rb}$ concentrations and varying $\mathrm{Ca}$ concentrations.

barley (figure 5), the enhancing effect of $\mathrm{Ca}$ is still present, although it is much smaller than at $1 \times 10^{-4}$ eq. per liter. The data indicate that, although Ca promotes the uptake of $\mathrm{Rb}, \mathrm{Rb}$ suppresses the uptake of $\mathrm{Ca}$. There are insufficient data to calculate whether this may be a competitive effect.

At concentrations around $1 \times 10^{-4}$ eq. per liter, the $\mathrm{Ca}$ uptake by plantain roots was about 10 times the $\mathrm{Rb}$ uptake. At concentrations around $10^{-2}$ eq. per liter (figure 6 ), the uptake of both ions are the same order if the ions are given alone. From the concentration curves it is calculated that $\mathrm{k}_{\mathrm{CaRb}}$ is about 4.9 for the uptake rates, and the replacement curves calculated with this value and equation [3] match very well the measured replacement curves. Hence, competition seems to be the predominate effect at these concentrations.

\section{Experiments at Constant $\mathrm{Ca}$ Concentration}

Since with both barley and plantain other than competitive phenomena are observed, it is necessary to check whether the effect of $\mathrm{Ca}$ can be overcome by increasing $\mathrm{Rb}$ concentrations. The graphs in figure 7 , with the $\mathrm{Rb}$ concentration along the abscissa in logarithmic progression, represent these results. The enhancing effect of $2 \times 10^{-4}$ eq. Ca per liter on the rate of $\mathrm{Rb}$ uptake by barley occurs over a large range of concentrations of $\mathrm{Rb}$. The sigmoid shape of the curves indicates again that at least two equations [2] are needed to describe the relation between concentrations and uptake. Increasing the $\mathrm{Rb}$ concentration did not overcome the effect of $2 \times 10^{-4}$ eq. Ca per liter on the uptake rate of $\mathrm{Rb}$ by plantain roots, although a calculation based on the data of figure $4\left(\mathrm{k}_{\mathrm{CaRb}}=2.3\right)$ shows that the depressing effect of $2 \times 10^{-4}$ eq. Ca per liter due to competition should be negligible at concentrations of $1 \times 10^{-2}$ eq. $\mathrm{Rb}$ per liter. This indicates that something other than competitive effects of $\mathrm{Ca}$ may decrease the $\mathrm{Rb}$ uptake.

\section{Experiments at Constant $\mathbf{R b}$ Concentrations}

The preceding data do not exclude the possibility that beyond a certain minimum concentration the effect of $\mathrm{Ca}$ on the $\mathrm{Rb}$ sorption is independent of $\mathrm{Ca}$ concentration. The graphs in figure 8 , with the $\mathrm{Ca}$ concentration along the abscissa in logarithmic progression, and the $\mathrm{Rb}$ uptake rates from $1 \times 10^{-4}$ eq. $\mathrm{Rb}$ per liter (barley) or $1 \times$ $10^{-3}$ eq. $\mathrm{Rb}$ per liter (plantain) along the ordinate, show that this is not the case. The enhancing effect of $\mathrm{Ca}$ on the $\mathrm{Rb}$ uptake by barley and the depressing effect of $\mathrm{Ca}$ on the $\mathrm{Rb}$ uptake by plantain increases with increasing $\mathrm{Ca}$ concentrations up to $1 \times 10^{-2}$ eq. $\mathrm{Ca}$ per liter (barley) and up to $1 \times 10^{-3}$ eq. Ca per liter (plantain).

\section{CONCLUDING REMARKS}

The results of this series of experiments show that the effect of $\mathrm{Ca}$ on the uptake of $\mathrm{Rb}$ by excised roots of barley and plantain is not consistent. Although competition between $\mathrm{Ca}$ and $\mathrm{Rb}$ exists with plantain roots, other interactions also occur. These observations place more rigid requirements on any explanation of the interactions of $\mathrm{Ca}$ and $\mathrm{Rb}$ uptake by excised roots.

The relative uptake rates of $\mathrm{Ca}$ and $\mathrm{Rb}$ by excised roots of barley and plantain are similar to the relative $\mathrm{Ca}$ and $\mathrm{K}$ contents of the whole plants. A test of whether $\mathrm{Ca}$ increases the uptake of $\mathrm{K}$ in growing plants is difficult because plants will not grow in a nutrient medium that does not contain Ca.

\section{LITERATURE CITED}

1. Bear, F. E. Cation and anion relationships in plants and their bearing on crop quality. Agron. J. 42:176-178. 1950.

2. Briggs, G. E., Hope, A. B., and Robertson, R. N. Electrolytes and plant cells. Oxford, 1961.

3. Collander, R. Selective absorption of cations by higher plants. Plant Physiol. 16:691-720. 1941.

4. De Wit, C. T. On competition. Verslagen Landb. Onderz. 66.8: 82 p. 1960.

5. Dijkshoom, W. The rate of uptake of chloride, phosphate, and sulphate in perennial ryegrass. Neth. J. Agr. Sci. 7: 194-201. 1959.

6. Epstein, E., and Hagen, C. E. A kinetic study of the absorption of alkali cations by barley roots. Plant Physiol. 27: 457-474. 1952 .

7. Fried, M., and Noggle, J. C. Multiple site uptake of individual cations by roots as affected by hydrogen ion. Plant Physiol. 33: 139-144. 1958.

8. Heald, W., Frere, M., and de Wit, C. T. Ion adsorption on charged surfaces. In press.

9. Said, I. M. Cation selectivity and cation-anion balance as factors governing the mineral composition of pasture herbage. Verslagen Landb. Onderz. 65.16: 64 p. 1959.

10. Sutcliffe, J. F. The selective uptake of alkali cations by red beet tissue. J. Exp. Bot. 8: 36-49. 1957.

11. Viets, Frank G., Jr. Calcium and other polyvalent cations as accelerators of ion accumulation by excised barley roots. Plant Physiol. 19: 466-480. 1944. 